\title{
Debate e investigación Creación en Internet: los nuevos museos de arte
}

José Ramón Alcalá Mellado

Catedrático de la Universidad de Castilla-La Mancha y director del MIDE

\section{Resumen}

Este artículo aborda las nuevas condiciones de la creación electrónica actual y su potencial divulgación a través de museos y galerias virtuales on-line a partir de las experiencias recogidas durante el desarrollo de los trabajos de investigación del Proyecto eGALAB (Virtual Galleries \& Laboratories for Electronic Art), perteneciente al programa CULTURE 2000 de la Unión Europea, desarrollado entre 2002 y 2003 por el MIDE (Museo Internacional de Electrografia) de Cuenca en colaboración con CIANT (Internacional Centre for Art and New Technologies) de Praga, y CYPRES (Centre Interculturel de Practiques, Recherches et Echanges Transdisciplinaires) de Marsella, y cuyo principal objetivo consistia en la creación de una nueva plataforma en la red Internet para la creación artística, la experimentación y la exhibición a partir del uso de nuevas tecnologias VRML (Virtual Reality Modeling Language), y su promoción y divulgación a través de galerias y museos virtuales, mediante interfaces y sistemas de navegación más potentes, versátiles e intuitivos."

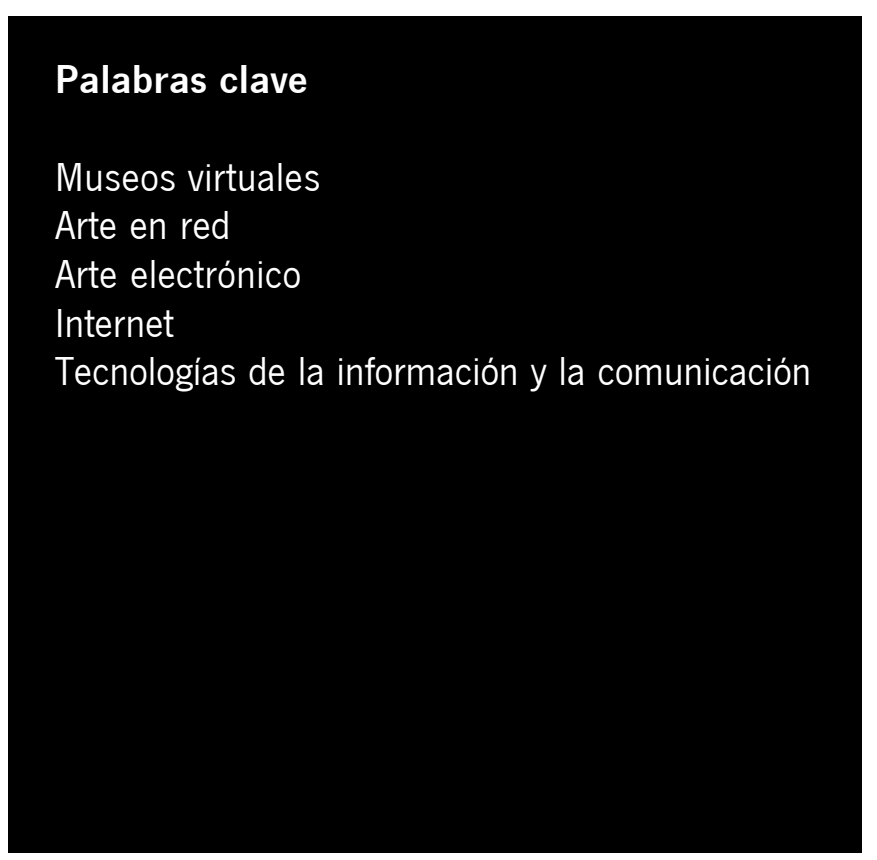

La necesidad de crear galerías y laboratorios electrónicos para el arte virtual refleja el estado de necesidad que tiene el artista digital a la hora de crear y presentar sus obras, así como la exigencia del campo museístico actual por utilizar el sistema on-line que le ofrece la red Internet como plataforma de divulgación y distribución de las obras de arte.

Aunque actualmente las galerías y museos están empezando a presentarse on-line de una manera popularizada, aún continúan tratando a los artistas y a sus obras de una manera anticuada. Incluso las galerías más avanzadas que se encuentran en la red basan sus sitios web en un simple tipo de navegación estructurado a partir del "señalar y pulsar", cuyo sistema funcional es tan limitado y hostil para las aspiraciones del artista como para la satisfacción del público. Existe además una falta de entendimiento entre la manera normal de representación del arte en galerías y museos y las formas artísticas emergentes, que se presentan directamente en soportes electrónicos (net-art, modelado virtual, animaciones interactivas, etc.).

Por otro lado, se observan grandes carencias y limitaciones de cara a un acercamiento intuitivo en el campo de entornos y comunidades virtuales dentro de las artes visuales y de las colaboraciones artísticas. Por ello, resulta totalmente necesario un nuevo tipo de galería que combine las ventajas de los espacios virtuales de la red Internet con los aspectos tradicionales de las creaciones y presentaciones artísticas.

Traspasar la frontera de las viejas tradiciones y dirigirse hacia las nuevas tendencias de las formas artísticas emergentes hace completamente necesaria la aplicación de los novedosos, potentes y versátiles procesos informáticos y telemáticos, a través de los cuales se puedan desarrollar plataformas multiusuario en 3D, con intuitivos sistemas de navegación en la red Internet y que sirvan como laboratorio y como galería de arte al mismo tiempo. De esta forma, los artistas podrian, no sólo presentar sus obras ya creadas en el mundo físico (lo cual ya se lleva a cabo hoy dia), sino también crear obras/piezas directamente a través de estos sistemas y presentarlas de forma continuamente actualizada en tiempo real mediante un completo sistema de navegación multimedia que incorporase sonido, música, imagen, animación y vídeo, dando así a los visitantes de este espacio virtual, no sólo información, sino también la posibilidad de seleccionar sus propios personajes virtuales (mediante avatares) que los representaran, permitiéndoles comunicarse interactivamente con otros visitantes y creadores a través de chats paralelos, animaciones y sonido.

La constitución de estos "Iugares virtuales para la representación" no requiere ya necesariamente de espacios representativos, como por ejemplo, habitaciones con paredes (tal y como las usamos en las galerías on-line al uso). De hecho, los nuevos espacios que, por ejemplo, se diseñaron para la galería virtual del proyecto eGALAB ${ }^{1}$, conformaban la propia espacialidad de sus 


\section{$062-063$ \\ Debate e Investigación}

Creación en Internet: los nuevos museos de arte

\section{PH46 - Diciembre 2003}

lugares a partir de la información misma, constituyendo todo un desafío, no sólo técnico, sino fundamentalmente conceptual.

Este nuevo planteamiento abre, qué duda cabe, un gran horizonte de posibilidades en torno a cómo crear y presentar una nueva generación de obras en espacios virtuales. Por nueva generación de obras, entendemos aquellas que dependen de espacios electrónicos desde su inicio y son creadas específicamente para dicho espacio. Los principales beneficiarios de estas nuevas galerías y espacios virtuales para la creación del nuevo arte electrónico y su difusión serán, sin lugar a dudas, los artistas, críticos de arte y estudiantes pertenecientes a escuelas de arte, que estén involucrados en la creación y experimentación de espacios virtuales con la ayuda de nuevas tecnologías; pero también está destinado a un extenso público interesado en arte y cultura que, tal vez, y a través del potencial creativo de estos nuevos sistemas, se involucre en los procesos artísticos, redefiniendo de una manera ampliada el concepto de artista -tal y como ya han hecho con el de obra de arte- y de público -ahora más usuario que nunca.

Definir las condiciones que deben procurarse para una correcta estrategia de virtualización de la distribución del arte on-line, dados los frecuentes malentendidos y las equivocadas estrategias adoptadas por la mayoría de los museos y galerías de arte, requiere analizar previamente las nuevas condiciones en las que se produce y en las que deben "vivir" las obras de arte digitalizadas y, sobre todo, las digitales.

Desobjetualizar el trabajo de creación artística no supone únicamente cambiar las herramientas de trabajo por las nuevas tecnologías electrónicas y digitales, sino todo un proceso de modificación del arte en sí mismo. Cambian los objetivos del artista, cambia la metodología de trabajo, cambia el esquema tradicional autor-obra-

\begin{abstract}
${ }^{1}$ Para más información sobre el proyecto eGALAB puede acceder a su página web, a través del enlace directo www.egalab.net o del link destacado en el sitio del Museo Internacional de Electrografía (www.uclm.es/mide). También, en la sección Proyectos y Experiencias de esta revista, encontrará un comentario específico sobre esta galería virtual.

1. Acción de creación compartida on-line dentro del Lab y Galería del proyecto eGALAB. Teatro Akrópolis. Praga. 2003

2. Representación sintética -según el sistema Motion Capture- de la modelo para la performance de presentación del Lab y Galería del proyecto eGALAB. 2003
\end{abstract}

espectador y cambian también las condiciones de distribución del producto. Nada queda en pie. Sin embargo, hasta ahora, en la mayoría de las ocasiones, los artistas han utilizado estos nuevos medios para modificar únicamente la naturaleza y el soporte de la obra, manteniendo los mismos objetivos y una casi idéntica metodología. También es cierto que esta revolución -que tiene su origen en la incorporación del ordenador en el ámbito de la producción artística en la década de los años 50-60 y su proceso evolutivo final en una red Internet madura a partir de mediados de la década de los años noventa-, no ha encontrado sistemas capaces de soportar algunos de los lógicos planteamientos conceptuales y discursivos que pensaron los artistas al unir el potencial de estos nuevos medios con planteamientos y propuestas que formularan el proceso creativo desde la madurez conceptual que permite ya una mirada histórica.

Hoy dia, resulta necesario ofrecer a los artistas sistemas telemáticos maduros capaces de contener y explotar la tremenda naturaleza del cambio en la concepción del hecho artístico que se atisba en un horizonte ya cercano. Un cambio que maneja conceptos y planteamientos hasta ahora inéditos, como es la posibilidad de que varios usuarios interactúen en un mismo tiempo y en un mismo lugar, de tal manera que posibilite la generación de actuaciones comunes fundamentadas en la acción en tiempo real, y con la posibilidad de que sus representaciones puedan ser de gran complejidad, esto es, realizadas a través de sistemas en 3D, con animaciones y una interactividad que supere el puro concepto de acción-reacción, o que todo ello pueda acontecer dentro de entornos inmersivos cercanos a la idea de la Realidad Virtual.

Cuando este tipo de entorno maduro es puesto a su disposición, son los mismos artistas los que de forma intuitiva e instantánea comprenden que están ante un nuevo sistema que exige realmente una actitud inédita ante la creación artística, una actitud

\section{Voces}

\section{Patrimonio y virtualidad}

José Lebrero Stals

Director del Centro Andaluz de Arte Contemporáneo

La implantación y el uso de las nuevas tecnologías en la gestión del patrimonio histórico tiene connotaciones especificas si lo que está en cuestión es la articulación de dispositivos de mediación social del arte contemporáneo. No hay duda, el empleo del hardware y software informáticos ofrecen enormes posibilidades para efectuar con mayor facilidad, eficacia y celeridad las actividades diarias de gestión y mediación pública de un centro de arte.
Sin embargo, a diferencia de cualquier otro tipo de situación museológica que se pueda plantear, la que atañe al cuidado de la producción visual reciente se encuentra irremediablemente enfrentada a nuevos tipos de obras artísticas que precisamente recurren a las nuevas tecnologias como soporte y como herramienta, y lo que todavía resulta más complejo como un espacio donde tener lugar no sólo la exhibición pública del discurso y su expansión, sino su misma gestación. El hecho de que los artistas hoy puedan idear y plantear su propuesta ex profeso para las redes universales de internet en línea significa por ejemplo que el acceso a la misma requiere inexcusablemente la condición de estar conectado al sistema. Ello se complica, si la intención del trabajo digital propuesto es participativa, de tal modo que los contenidos se transforman mediante la intervención en línea de los usuarios del sistema, variando de algún modo la formulación inicial planteada por el autor.

Si bien la fotografia, pasado un siglo largo de su aparición como invención, ya no es asunto de discusión en el debate sobre su po- 


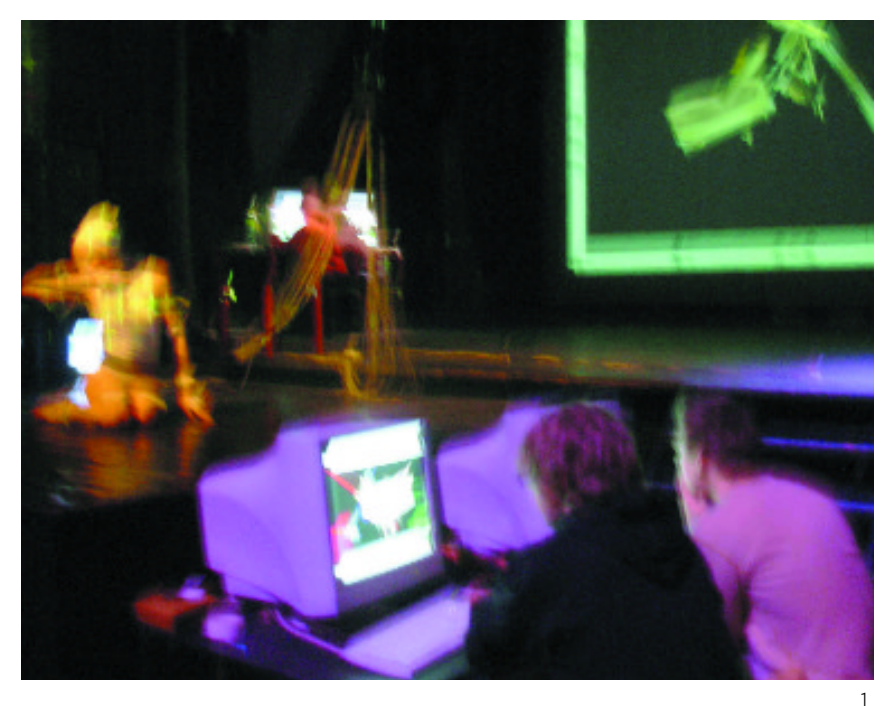

ya diametralmente opuesta a la formulación romántica que ha presidido el arte de nuestra sociedad occidental durante los últimos cinco siglos. Ellos mismos han definido este tipo de experiencia artística como algo más cercano a la actitud de un DJ que mezcla sonidos e imágenes en directo en un club de culto y ante una comunidad -tal vez todavía hoy contracultural y no mayoritaria, pero tremendamente coherente en sus objetivos y en sus pautas de comportamiento-, que ante la típica actitud del artista audiovisual tradicional.

Pero, por otra parte, cuando este tipo de experiencias se pone en funcionamiento gracias a un potente y novedoso sistema con características funcionales similares a las mencionadas anteriormente, surgen nuevos retos ante el artista (o creadores participantes de este tipo de experiencia). Existen, por ejemplo, decisiones conjuntas que tomar, reglas de comportamiento y de uso muy particulares que hay que pre-establecer. El trabajo en grupo -y sobre todo aquél que se fundamenta en un funcionamiento en tiempo real- exige otra actitud, otra mentalidad, un nuevo concepto de jerarquización de la "autoridad", que tomará decisiones sobre el work-in-progress ad-infinitum en que puede convertirse esta nueva experiencia de lo creacional.

Ahora tenemos la inercia de mirar hacia otros lados, hacia parcelas incipientes de este mismo campo de acción: Ios video-

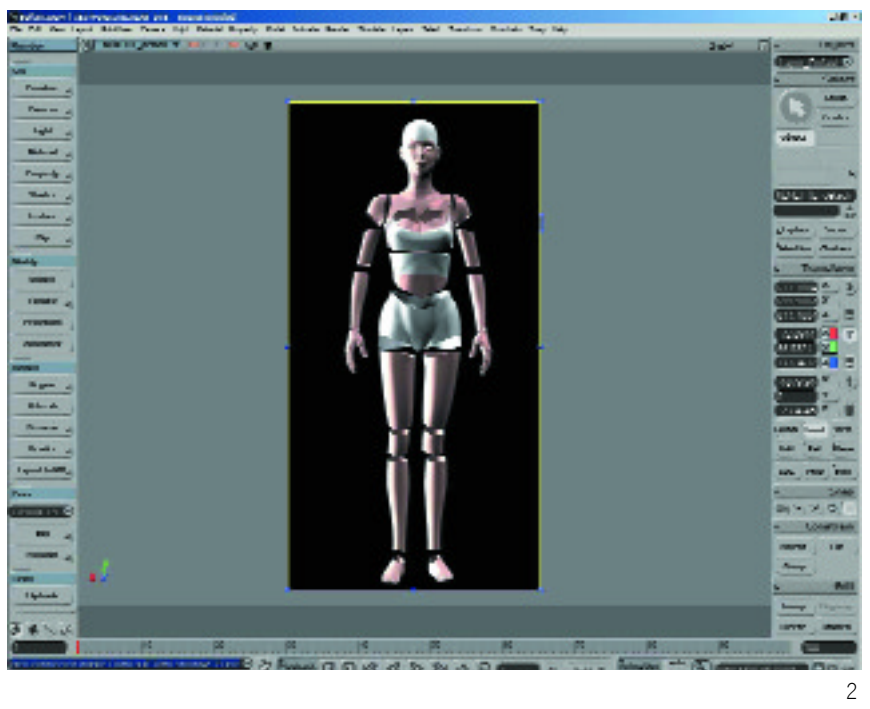

juegos, los chats de Internet, son algunos de los lugares hacia los que dirigimos espontáneamente nuestra mirada para encontrar referentes válidos, precedentes que hayan tenido que asumir decisiones similares al respecto: la figura del webmaster, la idea del invitado con o sin capacidad de decisión, el excluido por votación o por decisión "suprema" y, por otro lado, la cultura de la obra nunca terminada, siempre en proceso, la performance re-visitada, la idea de galería como el Museo Vacío, o la de salas de juego, dispuestas para que sea observado -por parte de ocasionales visitantes- el desarrollo de las acciones Ilevadas a cabo en ese momento por sus interactuantes. Perderemos entonces la idea de autoría como la obra de un único autor, la idea de obra terminada, la idea de objeto dispuesto para ser expuesto. Muchos de los procesos contemporáneos, como el vídeo, el multimedia interactivo, etc. encontrarán otros desarrollos discursivos, otras plataformas de aplicación, otros lenguajes, abriendo nuevos campos de acción creativa.

Pero quizás, el punto más caliente, el que sufre un proceso de transformación más traumático y que es consecuencia de la puesta en funcionamiento de la memoria de todas las acciones realizadas por el proceso antes descrito es, sin lugar a dudas, el de la Galería como espacio para la contemplación de las obras y las acciones ya realizadas. sible valor como patrimonio artístico, no sucede lo mismo con el empleo de otros medios tecnológicos. Huelga considerar el caso del cine, ya que interesó pronto a los creadores de las vanguardias para explorar narrativas diversas -desde su empleo como herramienta de agitación social por El Lissitzky hasta las formulaciones oníricas de Jean Cocteau-. Poseedor de una propia historia y aunque todavia con lagunas de experimentación que están pendientes de normalización patrimonial, la relación del cine con las artes visuales, las representaciones propias de la historia del arte convencional, parece consolidada. No sucede así con el vídeo. Únicamente en el pasado reciente se ha podido comprobar un proceso de auténtica normalización en lo que concierne a la aceptación de las producciones videográficas por parte de los museos.

¿Cómo? Mediante el procedimiento eficaz por excelencia: el incremento de adquisiciones de producciones videográficas por las colecciones públicas y privadas de arte contemporáneo ha experimentado en la pasada década una progresión inimagina- ble a finales de los años ochenta. No puedo entrar aqui en un análisis detallado de este fenómeno que ayude a comprender a qué responde este enorme interés por el vídeo como modo de expresión artística. Lo cierto es que hacia finales de los años sesenta, el descubrimiento de la handy-cam, una cámara portable de vídeo de fácil manejo fue decisivo. Se trataba de un soporte alternativo al cine, que posibilitaba técnica y económicamente la producción doméstica del rodaje con la gran ventaja de facilitar de modo inmediato el visionado de los resultados de la filmación. Pero lo que considero más importante, es el hecho de que ofrecía al artista crítico con el discurso dominante y los cánones de la época un soporte para la representación insólito hasta entonces y no lastrado, pues, de ideología e historia como era el caso de la pintura, la escultura o incluso la propia fotografia.

En el devenir de la historia de la imagen surgirá un nuevo estadio en esta progresiva apropiación para fines no estrictamente informativos o documentales de las nuevas tecnologias. Un sector de 


\section{$064-065$ \\ Debate e Investigación}

Creación en Internet: los nuevos museos de arte

\section{PH46 - Diciembre 2003}
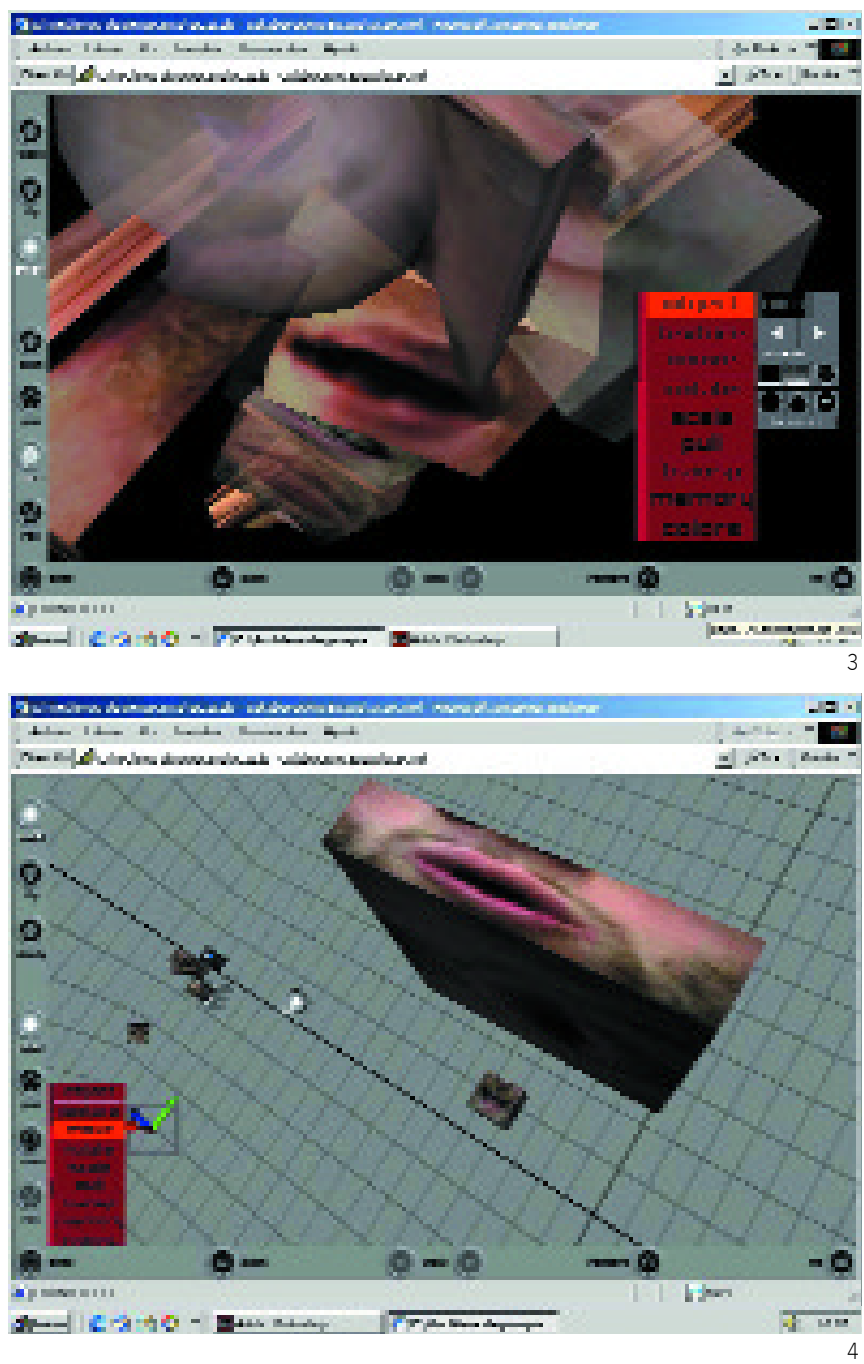

3. Barra de menú siendo utilizada por un artista actuando on-line en el Lab del proyecto eGALAB. 2003

4. Barra de menú siendo utilizada por un artista actuando on-line en el Lab del proyecto eGALAB. 2003
Después de múltiples y apasionantes sesiones de reflexión y debate sobre la evolución y los resultados obtenidos en el desarrollo las acciones prácticas realizadas durante los casi nueve meses de trabajo por parte de los artistas, ingenieros y programadores participantes en el proyecto EGALAB (poniendo en funcionamiento las consecuencias del dispositivo ahora creado), se erigió en común opinión otorgarle a la simple y automática acción de "record + save" el paradigma fundamental que soportaría por si sola a la re-definida Galería de Arte virtual, cuyo valor patrimonial o expositivo no es ya sino un simple indice en constante actualización en tiempo real y on-line sobre los contenidos generados en su propio taller virtual de creación.

Ante la insistencia, o más bien, la tendencia inercial hacia una tridimensionalización de la representación de la información gráfica, los resultados obtenidos en este proyecto, llevó también a afirmar que ésta no siempre presupone la consecución de la solución ideal, sobre todo porque, en lo que se refiere a las galerias virtuales, al final, los sistemas que se imponen, los más limpios conceptualmente y por tanto los más eficaces, son aquellos que trabajan con la idea de data-base y de la información indicial; lo que suele venir soportado por estructuras muy minimalistas -casi puros códigos de programación visualizados, que se alejan completamente del modelo convencional de representación en 3D.

En cualquier caso, producir o ayudar a producir supone siempre un acto de patrimonialización y, por tanto, tener un producto que ofrecer al público. Y querer ofrecerlo supone la autoexigencia de una mínima taxonomía. Algo totalmente necesario en aras a una información que se ofrece organizada y capaz de generar conocimiento. los artistas interesados en el pensamiento en movimiento y en el fluir de las ideas complejas, se interesa por lo digital. La democratización del acceso a los ordenadores y la mundialización de los sistemas capaces de enlazar redes de menor tamaño permiten ahora la transmisión de datos entre cualquier par de ordenadores conectados a estas redes subsidiarias. La conexión a internet ha generado una malla de ámbito mundial. Ello supone no sólo la aparición de un nuevo tipo de relación entre artista y espectador sino que obliga en mi opinión a la institución de mediación -en nuestro caso el museo de arte contemporáneo- a realizar una reflexión profunda sobre el papel que quiere y puede jugar en el futuro inmediato de la creación artística. El museo se encuentra hoy partícipe en la era que de un modo difuso y genérico se conoce como la sociedad de la información y el conocimiento.

Tres son básicamente los retos a los que se enfrenta el museo de arte contemporáneo en relación a lo anterior. La cuestión que se plantea es cómo reaccionar ante la implantación de las nuevas tecnologías en todos los ámbitos de la existencia de los ciudadanos en las sociedades democráticas que apuesten por programas progresistas para salvaguardar el bienestar de los ciudadanos frente a la avalancha mediática manipulativa que recorre la red. Por una parte posibilitando la articulación de sus programas en red. Esto afecta a las exposiciones, publicaciones, actividades, patrimonio y programas educativos. La modernización de la difusión permite llegar a segmentos de poblaciones hasta hace poco, sin duda, inaccesibles. Para ello internet juega un papel fundamental. Limitarse a utilizar la red como un tablón de anuncios de actividades es perder la partida anticipadamente. Mucho más arriesgado y atractivo es buscar la complicidad con el medio, sus agentes y sus usuarios para elaborar nuevos discursos de mediación naturalizados en los entornos digitales.

El segundo de los retos apuntados aquí consiste en apostar por la creación digital. Recurrir a uno de los mecanismos más contundentes de que disponemos: la adquisición patrimonial. Es 
5, 6 y 7. Modelos pertenecientes a las últimas propuestas del diseño y conceptuación de la Galería Virtual del proyecto eGALAB

Así pues, en las relaciones de tensión, fluctuación y convivencia que, de forma espontánea y automática, se produce entre el crear y su divulgación (como acto exhibicionista del mostrar lo acumulado, lo coleccionado) se construye todo un nuevo paradigma del acto de la creación contemporánea. Aquella que ha asumido la utilización de los nuevos medios tecnológicos y que, sólo a través de sistemas maduros -técnica y expresivamente-, permite ahora al artista profundizar en su viaje hacia los presupuestos dictados por un arte electrónico -convertido ya en pura comunicación virtualizada, y en donde el fluir de la información (audiovisual, multimedia, retroactiva) se convierte en el soporte para la construcción de todo lenguaje.

Evidentemente, sólo desde presupuestos discursivos bastante elaborados y desde estructuras narrativas predeterminadas -basadas en poéticas personales (aplicadas de manera espontánea o premeditada)-, se lograrán resultados que podremos considerar de indudable interés artístico. Aunque, tal vez, esta opinión pudiera estar efectuada desde los esquemas parametrales tradicionales de evaluación de la actividad artística que hemos denostado anteriormente.

Seguro que cualquier sitio web diseñado y construido para albergar todo este nuevo complejo proceso de creación-distribución definido anteriormente como una nueva galería virtual y on-line para el Arte necesitará regirse a partir de unas reglas de comportamiento y de uso inicialmente predeterminadas, acordes a su nueva forma operacional y a su nuevo concepto comunicacional y creativo, pero que, sin duda alguna, serán modificadas y mejoradas por el propio uso y destino que le den sus usuarios potenciales (con toda probabilidad miembros de espontáneas comunidades virtuales creadas al pairo de intereses específicos comunes). Muy probablemente también, los lenguajes creativos que emerjan de sus creaciones, de sus producciones, de sus acciones, estarán cons-
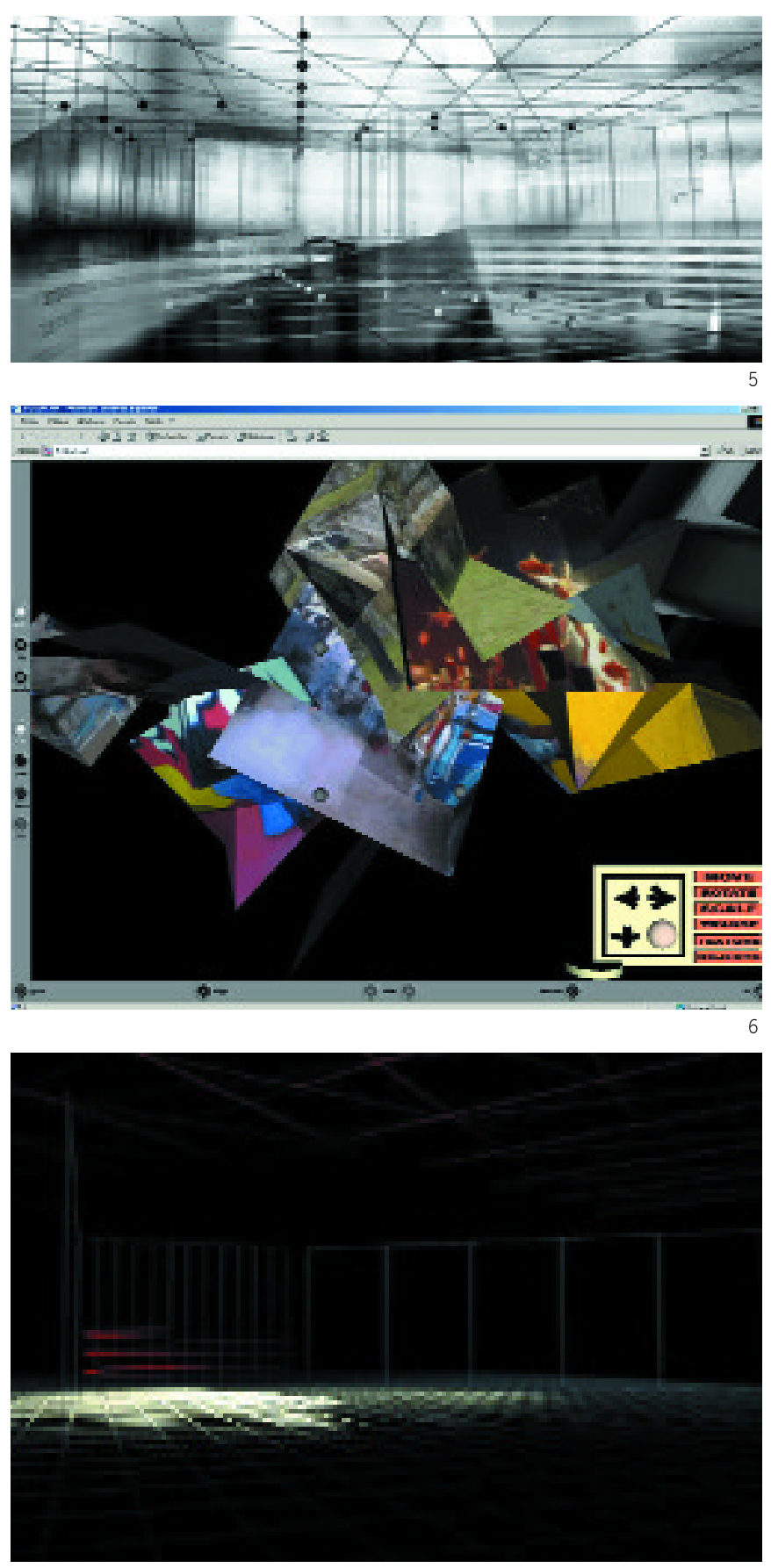

cierto que se trata de una estrategia de ampliación de la misma idea de colección, que sugiere no pocos problemas técnicos e incluso legales a resolver y no menos desacuerdos ideológicos en relación a la oportunidad de legitimación social de un tipo de propuestas aún en emergencia. Sin embargo los hechos van por delante de las diatribas y el número de instituciones públicas dedicadas al arte contemporáneo que producen y coleccionan obras realizadas gracias a las nuevas tecnologías va en un aumento imparable. Por lo tanto, de ser afirmativa, la apuesta es para hoy.

Finalmente el quizás más complejo y apasionante de los tres retos que mencionaba consiste en entender el centro de arte como un espacio más en la red. Para ello, nuevos escenarios están surgiendo en la virtualidad. No por ello hay que dejar de reivindicar la excelencia de la experiencia física directa que nos facilita, por ejemplo, la experiencia perceptiva del encuentro inmediato con la obra, sea esta lo que sea y esté realizada en cualquiera de los múltiples soportes actuales, en una sala de exposiciones. Los nuevos son escenarios digitales caracterizados por la ubicuidad, lugares de anónima adscripción geográfica que únicamente resulta posible localizar gracias al sistema de navegadores en red. Uno de los futuros presentes del museo de arte contemporáneo que se rebele a ser únicamente un contenedor de objetos del pasado, en mi opinión, está precisamente alli, en la maraña infinita de la red. Las formas de convertir en presencia museística esta vocación de arqueólogos del futuro interesados en conjugar arte con ciencia con educación son varias. Una de las más eficaces y que apuntan hacia delante consiste en la construcción en red de espacios de exhibición y trabajo. No me refiero al consabido y frecuentemente limitado concepto de "visita virtual", una traducción insuficiente a la pantalla del espacio físico del museo. Más bien de lo que se trata es de la elaboración de proyectos que cumplan con las misiones características de los centros dedicados a la contemporaneidad, pero apropiándose de las peculiaridades que ofrece la red: entre otras interdisciplinariedad, sincretismo o entropia. 


\section{$066-067$}

\section{Debate}

e Investigación

Creación en Internet: los nuevos museos de arte

\section{PH46 - Diciembre 2003}

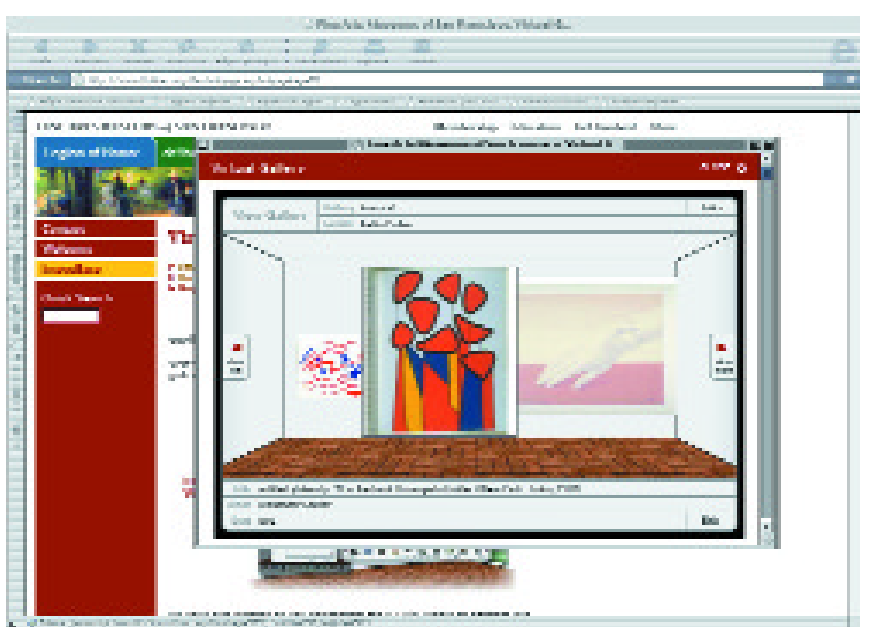

truidos a partir de soluciones espontáneas debidas al uso y abuso del propio sistema (tal y como ya ha ocurrido otras tantas veces) y que, como ejemplo más reciente, podemos ejemplificar con la aparición del lenguaje de los emoticones para la comunicación y la creación a través de los sistemas de la telefonía móvil.

Hemos de confiar por tanto en el desarrollo de sistemas que soporten a aquellos nuevos lenguajes que darán forma al imaginario subconsciente colectivo de una sociedad que ha aprendido a repensarse como una nueva entidad diferenciada de sus antecesoras, pero que necesita reconocerse en la imagen del espejo en el que se mira. Y para ello, nada mejor que apoyar, mediante convocatorias desde lo público y lo privado, a aquellos proyectos de investigación -y a aquellas entidades artísticas- que aporten soluciones en este sentido, que dirijan sus esfuerzos en esta dirección creativa.

Contacto: JoseR.Alcala@uclm.es

\section{Bibliografía}

\section{Bibliografía específica sobre el tema}

ALCALÁ, José Ramón: “Arte y Nuevas Tecnologias en el siglo XXI. Museo de Arte vs Centro de Arte Contemporáneo. Producir y coleccionar (no)obras de arte actual. ALMAZÁN, D. et LORENTE, J.P.: Museología crítica y arte contemporáneo. Ed. Universidad de Zaragoza. Zaragoza. 2003

ALCALÁ, José Ramón: "Sistemas telemáticos compartidos: Arquitecturas virtualizadas para un nuevo modelo de creación y la exhibición del arte electrónico contemporáneo". Binaria. Vol.III. Verano 2003. Univeridad Europea Madrid. On-line.

ALCALÁ, José Ramón: "El Artista Global. Nuevas identidades emergentes. Procesos creativos inéditos para un concepto ampliado de Patrimonio Cultural". Culturtec 2002. III Conferencia Europea. Empleo y Patrimonio Cultural, Promoción Económica y Nuevas Tecnologías en la Sociedad de la Información y del Conocimiento. Actas del Congreso. Facultad de Ciencias de la Información. Universidad Complutense de Madrid. Madrid. 22/05/02-24/05/02
8. Sistema de navegación del recorrido virtual por las salas de exposiciones de la web del San Francisco Museum of Modern Art.

ALCALÁ, José Ramón: "El museo ante el reto de las nuevas tecnologías en el siglo XXI". Revista de Museología. \#21. Dossier: "Museos del siglo XXI, la apuesta por las nuevas tecnologías". Madrid. 2001. pp.48-60.

ALCALÁ, José Ramón: "Las nuevas tecnologias en el mundo de los museos". ${ }^{\circ}$ Congreso Internacional de Museología del Dinero. Museo Casa de la Moneda. Madrid. 18/10/99. Internacional. Actas del Congreso. pp.51-55.

CENTURY, Michael: "Pathways to Innovation in Digital Culture". Centre for Research on Canadian Cultural Industries and Institutions / Next Century Consultants, Montreal, July 7, 1999 (Estudio financiado por The Rockefeller Foundation, Arts and Humanities Division).

COOK, Sarah, GRAHAM, Beryl at MARTIN, Sarah: Curating New Media. Baltic. B.Read Series /Six. Gateshead (G.B.). 2001.

VV.AA.: Revista de Museología. \#21. Dossier: "Museos del siglo XXI, la apuesta por las nuevas tecnologías". Madrid. 2001.

\section{Otra bibliografía de interés}

ALCALÁ, José Ramón: "Ciencia, filosofia, pensamiento abstracto y sensorialidad individual". Contrastes. \#10. Monográfico: "Democratización de las Nuevas Tecnologías". Valencia. junio-julio 2000. pp.56-63.

ALCALÁ, José Ramón: "Cultura, modelo y creación en el tercer milenio". Componente Norte. Revista de Arte, Literatura y Humanidades. \#4. Santander. 1999. pp.32-39.

BATESON, BIRDWHISTELL, GOFFMAN, et Alt.: La Nueva Comunicación. Ed. Kairós. $4^{\circ}$ Edición. Barcelona 1994.

BAUDRILLARD, Jean: La guerra del Golfo no ha tenido lugar. Ed. Anagrama. Col. Argumentos. \#120 Barcelona, 1991.

BREA, José Luis: La Era Postmedia. Acción comunicativa, prácticas (post)artísticas y dispositivos neomediales. Ed. Centro de Arte de Salamanca. Col. Argumentos \#1. Salamanca. 2002.

CARRASCOSA, José Luis: Quimeras del conocimiento. Mitos y realidades de la Inteligencia Artificial. Fundesco. Col. Impactos. Madrid 1992.

DE KERCKHOVE, Derrick: La piel de la cultura. Investigando la nueva realidad electrónica. Ed. Gedisa. Barcelona 1999.

DE KERCKHOVE, Derrick: Tecnología y Cultura, Ed. Gustavo Gili, Col. Tecnología y Sociedad, Barcelona, 1978.

DRUCKREY, Timothy (Editor): Electronic Culture; Technology and Visual Representation. Ed. Aperture Foundation Inc. Ontario. 1996.

GIANNETTI, Cludia, (coord.): Arte en la Era Electrónica. Perspectivas de una nueva estética. Ed. L'Angelot. Barcelona 1997.

GIANNETTI, Cludia, (coord.): Media Culture. Ed. L'Angelot. Barcelona 1995.

MALDONADO, Tomás : Lo real y lo virtual. Ed. Gedisa. Col. Multimedia.\#8. Barcelona 1994

NEGROPONTE, Nicholas: El Mundo Digital, Ediciones B, Barcelona 1995.

QUEAU, Philippe: Lo Virtual. Virtudes y vértigos. Ed. Paidós. Hipermedia \#1 Barcelona 1995

WOOLLEY, Benjamin: El Universo Virtual. Acento Editorial. Col.SIGNOMAS, \#15, Madrid 1994. 